\title{
Estudo farmacológico do óleo essencial de vários tipos de pimentas.
}

\author{
J. M. ROSA ${ }^{1}$, L. MARTINELLI ${ }^{1}$, C. S. BRAGINE ${ }^{1}$, M. H. OKURA ${ }^{2}$ e A. C. G. MALPASS ${ }^{1}$ \\ ${ }^{1}$ Universidade Federal do Triângulo Mineiro, Faculdade de Engenharia Química \\ ${ }^{2}$ Universidade Federal do Triângulo Mineiro, Departamento de Engenharia de Alimentos \\ E-mail para contato: lairamartinelli@gmail.com/acgmalpass.uftm@gmail.com
}

\begin{abstract}
RESUMO - A atividade biológica de pimentas é uma análise de grande importância, podendo ajudar em pesquisas futuras. Para realizar essas análises foram utilizados dois métodos de extração, o Soxhlet e o Clevenger. Esses consistem na desidratação das pimentas com o solvente, obtendo assim o óleo que será analisado. As atividades biológicas foram realizadas com três bactérias e um fungo, até o presente momento. Entre todas as seis pimentas analisadas, a pimenta que apresentou melhor inibição nos dois métodos em todas as bactérias e no fungo, foi a pimenta rosa.
\end{abstract}

\section{INTRODUÇÃO}

As plantas aromáticas têm sido utilizadas desde os tempos antigos devido a sua atividade conservante, por suas propriedades medicinais e por conferir aroma e sabor aos alimentos. As propriedades farmacêuticas das plantas medicinais são atribuídas parcialmente aos óleos essenciais dessas plantas. Os óleos essenciais são produtos naturais complexos, constituído de um sistema multi-componentes compostos principalmente de terpenos e alguns compostos não terpenóides. Existem várias técnicas que podem ser utilizadas para extrair óleos essencias de várias partes diferentes de plantas aromáticas, incluindo a água, a extração com solvente, a expressão sob pressão, fluído supercrítico e extração com água subcrítica [Edris, 2007].

Os óleos essenciais são Produtos Naturais de importância química e farmacológica já comprovada. As propriedades farmacológicas desses produtos favorece a aplicação desses em diversos segmentos como: alimentício, medicinal e também tecnológico. Esse trabalho será o início de um grande estudo que envolverá a aplicação de óleos essenciais para fins tecnológicos. O presente projeto teve como objetivo extrair o óleo essencial de algumas espécies de pimentas e avaliar a atividade antibacteriana desses óleos essenciais. As pimentas analisadas foram: pimenta bode, pimenta dedo-de-moça, pimenta-do-reino branca, pimentado-reino preta, pimenta rosa e pimenta síria.

\section{METODOLOGIA}

Para a extração com Soxhlet, iniciou-se com o devido preparo das pimentas (trituração no caso das pimentas em grãos e cortes pequenos nas demais pimentas), bem como com a pesagem de cada uma delas. Em seguida, adicionou-se acetona ao balão de fundo e no Soxhlet colocou-se a quantidade pesada da pimenta entre duas camadas de algodão. Montou- 
se toda a aparelhagem e a extração foi realizada por aproximadamente 3 horas sob aquecimento. Após esse tempo foi obtido óleo juntamente com o solvente que pôde ser separado utilizando o evaporador rotativo.

O método utilizando o extrator Clevenger consiste em um sistema de arraste à vapor d'água. A água é aquecida em um balão de fundo redondo de $500 \mathrm{ml}$ sobre uma manta aquecedora e entra em ebulição, os vapores de água resultantes desse processo são conduzidos sob pressão em direção a outro recipiente, onde se encontra o óleo essencial. O calor do vapor faz com que as paredes celulares se abram. Dessa forma, o óleo que está entre as células evapora junto com vapores de água e os voláteis são conduzidos em direção ao condensador que vai para o tubo de resfriamento. Por serem menos densos, os óleos essenciais ficam concentrados sobre a camada de água, podendo ser facilmente separados no próprio equipamento, que contém uma bureta acoplada. Esta metodologia durou aproximadamente duas horas.

Posteriormente foram feitas as análises microbiológicas. Para este fim foram usadas as bactérias Bacillus cereus, Staphylococus aureus e Escherichia coli. Essas análises consistem na preparação de várias placas de Petri contendo o meio PCA - Plate Count Agar, Kasvi. Com o auxilio de um $s w a b$, foi colocado neste meio uma solução cotendo a bactéria diluída em $9 \mathrm{~mL}$ de salina $01 \%$. Em seguida, quatro papéis filtros autoclavados em formato de circulo, foram submersos em cada óleo e em seguida colocados nas placas, as quais foram colocadas em uma estufa bacteriológica, mantendo-as em uma temperatura $37^{\circ} \mathrm{C}$, exceto para o fungo que foi mantido a $25^{\circ} \mathrm{C}$. Após $24 \mathrm{~h}$ foram feitas as medições dos respectivos halos de inibição.

\section{RESULTADOS}

A partir das metodologias aplicadas, obtiveram-se os óleos que foram analisados. Colocados os valores em gráficos para melhor visualização, temos 4 gráficos a serem analisados. $\mathrm{O}$ eixo $\mathrm{x}$ representa as pimentas utilizadas e o eixo y representa a inibição que $\mathrm{o}$ óleo da pimenta analisada obteve sobre a bactéria/fungo. Essa inibição significa o halo de inibição alcançado pelo óleo.

As análises realizadas com a bactéria Escherichia coli mostra bons resultados para todos os óleos, exceto para o óleo da pimenta dedo-de-moça. De acordo com o Gráfico 1, vemos que o óleo da pimenta rosa no Soxhlet foi o óleo que mais inibiu o crescimento da bactéria. O mesmo pode ser visto a partir da Figura 1. 


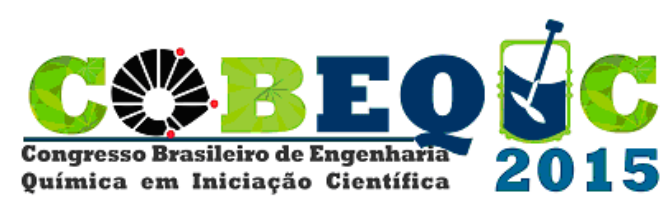

Química em Iniciação Científica 2015
XI Congresso Brasileiro de Engenharia

Química em Iniciação Científica

Unicamp - Campinas - SP

19 a 22 de julho de 2015
Gráfico 1 - Inibição da bactéria E. coli.

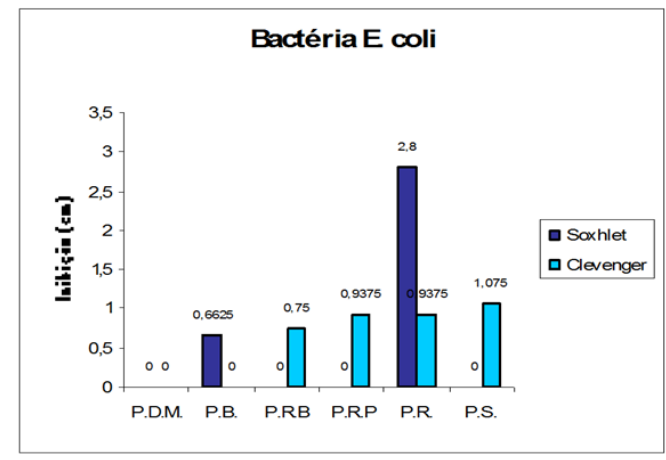

Figura 1 - Placa de Petri da Pimenta Rosa com a bactéria E. coli

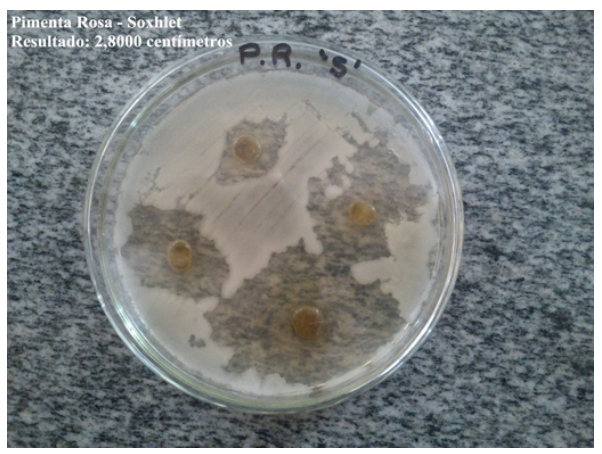

Para a bactéria Bacillus cereus, os óleos de apenas duas pimentas apresentaram bons resultados, confirmando o óleo da pimenta rosa (pelo método Clevenger) novamente como a melhor, como pode ser visto pelo Gráfico 2:

Gráfico 2 - Inibição da bactéria $B$. cereus

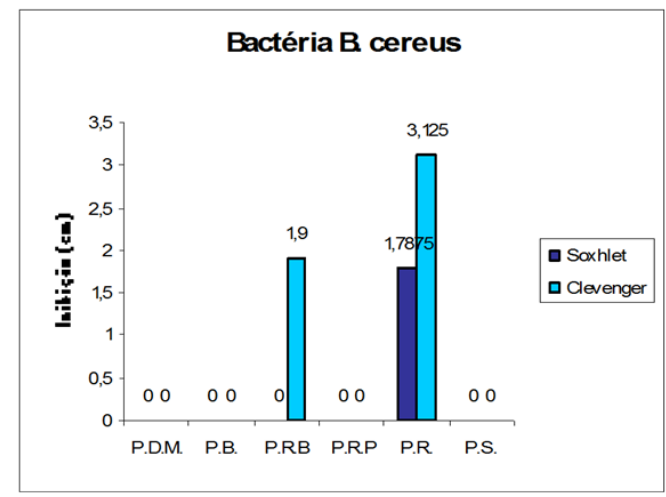

Figura 2 - Placa de Petri da Pimenta Rosa com a bactéria $B$. cereus

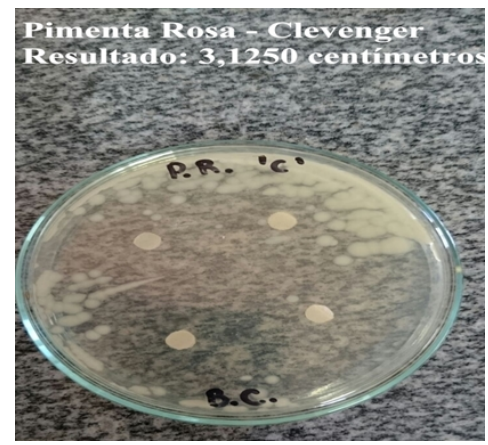

Nas análises com a bactéria Staphylococcus aureus confirmou-se novamente o poder inibidor da pimenta rosa, o que pode ser visto pelo Gráfico e Figura 3. Esta figura apresenta a placa de Petri tanto para o método Soxhlet quanto para o método Clevenger. 


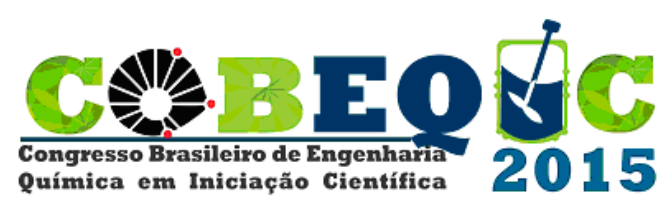

Química em Iniciação Científica 2015
XI Congresso Brasileiro de Engenharia

Química em Iniciação Científica

Unicamp - Campinas - SP

19 a 22 de julho de 2015

Gráfico 3 - Inibição da bactéria $S$. aureus

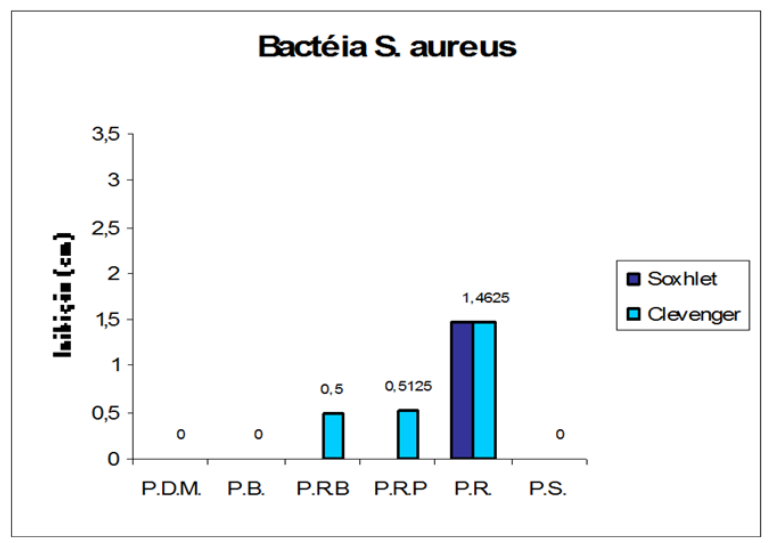

Figura 3 - Placa de Petri da Pimenta Rosa com a bactéria $S$. aureus.
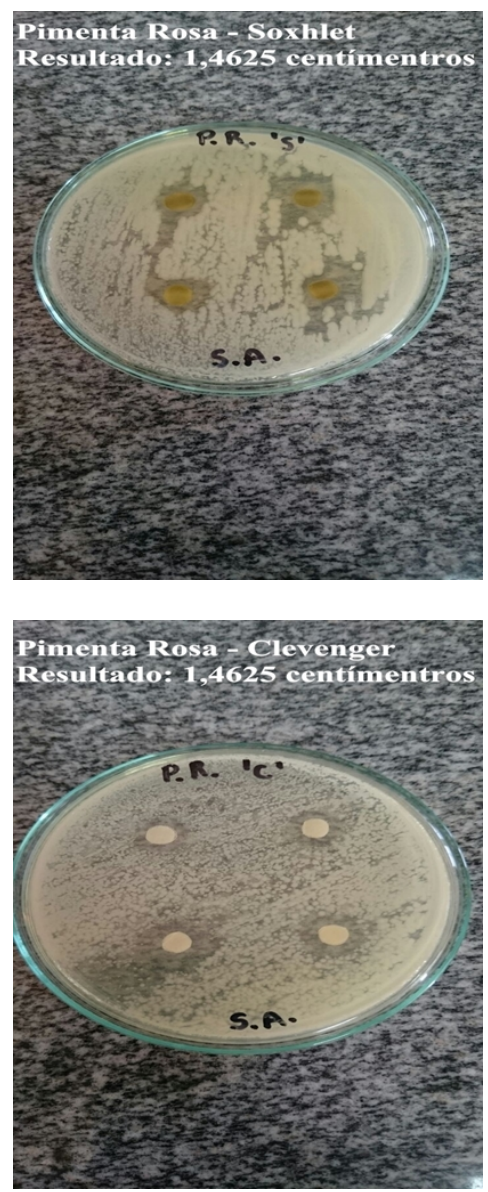

As análises apresentadas até o momento foram análises feitas com bactérias, mas pretende-se ainda realizar a atividade antifúngica dos óleos obtidos. Uma análise prévia com fungo Candida albicans, também evidenciou o óleo da pimenta rosa como o melhor inibidor para esse fungo. Análises com outros fungos ainda serão realizadas. Os resultados obtidos para C. albicans podem ser vistos no Gráfico e na Figura 4: 
Gráfico 4 - Inibição do fungo $C$. albicans

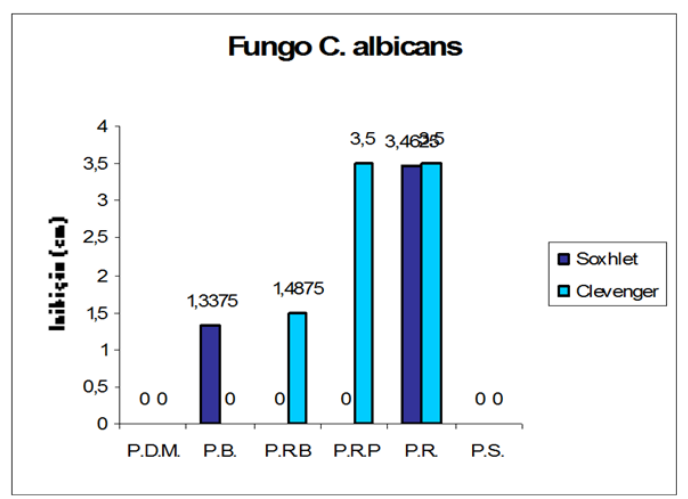

Figura 4 - Placa de Petri da Pimenta Rosa com o fungo C. albicans

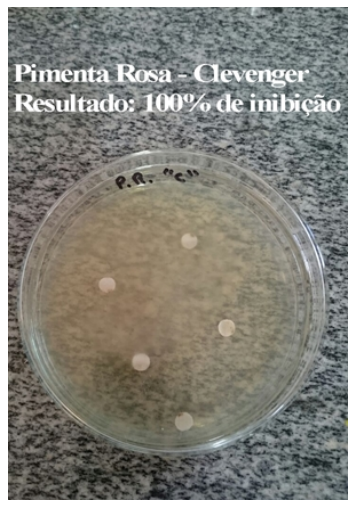

\section{CONCLUSÃO}

Até o presente momento, pode-se concluir que as pimentas em grão possuem uma maior atividade inibitória que as outras pimentas, e entre elas, a pimenta rosa é a que possui um poder inibitório maior, tanto para bactérias quanto para fungos. Analisando-se todas as figuras e gráficos, a menor inibição que ela teve foi de $0,9375 \mathrm{~cm}$, esse valor é grande se comparado a outros valores obtidos, pois em nossa análise, o óleo estava concentrado em apenas um ponto, e ao redor desse ponto, em torno de um centímetro não havia bactéria.

Já o resultado para o fungo testado até o momento é surpreendente, pois o óleo de pimenta rosa foi capaz de inibir $100 \%$ do fungo que foi colocado à prova. Até esse ponto do trabalho pode-se dizer que o óleo de pimenta rosa é o melhor para aplicação tecnológica em projetos futuros do grupo de pesquisa.

\section{NOMENCLATURA}

- P.B. - Pimenta Bode;

- P.D.M. - Pimenta dedo-de-moça;

- P.R.B. - Pimenta-do-reino Branca;

- P.R.P - Pimenta-do-reino Preta;

- P.R. - Pimenta Rosa;

- P.S. - Pimenta Síria 


\section{REFERENCIAS}

Bergonzelli G, Donnicola D, Porta N, Corthésy-Theulaz I. 2003. Essential oils as components of a diet-based approach to management of Helicobacter infection. Antimicrob Agents Chemother 47: 3240-3246.

Edris, A. E. Pharmaceutical and Therapeutic Potentials of Essential Oils and Their Individual Volatile Constituents: A Review, Phytother. Res. 21, 308-323 (2007).

Burt S. 2004. Essential oils: their antibacterial properties and potential applications in foods a review. Int J Food Microbiol 94: 223-253.

CLSI - Clinical and Laboratory Standards Institute. Performance standards for antimicrobial susceptibility testing; 16th informational supplement. M100-S16. Clinical and Laboratory Standarts Institute, Wayne, PA. 2006. 